\title{
УДК 352/353
}

БУКАЛОВА Светлана Владимировна - кандидат исторических наук, доцент; доцент кафедры политологии и государственной политики Среднерусского института управления - филиала Российской академии народного хозяйства и государственной службы при Президенте РФ (302028, Россия, г. Орел, б-р Победы, 5a; stl1612@yandex.ru)

МЕРКУЛОВА Ксения Геннадьевна - кандидат политических наук, доцент кафедры политологии и государственной политики Среднерусского института управления - филиала Российской академии народного хозяйства и государственной службы при Президенте РФ (302028, Россия, г. Орел, б-р Победы, 5a; kseniia.merkulova@gmail.com)

\section{«ДЕМОКРАТИЯ МАЛЫХ ПРОСТРАНСТВ»: ЭВОЛЮЦИЯ ИНСТИТУТА МЕСТНОГО САМОУПРАВЛЕНИЯ В РОССИИ В КОНТЕКСТЕ ИДЕЙ А.И. СОЛЖЕНИЦЫНА}

Аннотация. Статья исследует имплементацию взглядов А.И. Солженицына на местное самоуправление в современную практику развития этого института. Авторы сопоставляют содержание государственной политики в отношении местного самоуправления с концепцией «демократии малых пространств», предложенной А.И. Солженицыным и прочно вошедшей в официальный лексикон, и приходят к выводу о существовании противоречий между требованиями экономической эффективности и демократичности системы местного самоуправления. Это актуализирует требование поиска новых форм взаимодействия с жителями в рамках укрупненных муниципалитетов.

Ключевые слова: местное самоуправление, государственная политика, муниципальная реформа, прямая демократия, А.И. Солженицын

И нститут местного самоуправления играет важную роль в общественнополитической жизни и организации низового уровня социального управления, являясь многоаспектным понятием. Его принято рассматривать как политический, правовой и социальный институт, сочетающий властное начало и принцип самоорганизации. Эволюция института местного самоуправления в России имеет непростую траекторию. В настоящее время наша страна стоит на пороге реформы конституционных основ организации местного самоуправления, что актуализирует необходимость уточнения политико-идеологических основ построения отечественной системы местного самоуправления. Концептуальное решение данной задачи позволит точнее определить raison d'être, а следовательно и круг компетенции местных органов, принципы их взаимодействия с региональной и федеральной властью, а также с населением.

Существующая в РФ система местного самоуправления создавалась как определенная антитеза советской системе органов власти и подразумевала разделение местного самоуправления и государственной власти, предусматривающее наделение первого автономией. Исследователи отмечают, что на этом этапе возникла задача «нравственной реабилитации» идеи независимого местного самоуправления в глазах жителей [Меркулов и др. 2018: 221].

Отчасти решение этой задачи принял на себя А.И. Солженицын, возвратившийся на родину из эмиграции в 1993 г. в статусе «совести нации». Еще в 1990 г. в России многомилионным тиражом было издано его публицистическое эссе «Как нам обустроить Россию?», в котором писатель касался различных сторон государственного строительства. Важным элементом этого видения стала авторская концепция местного самоуправления, сформулированная на основе 
знакомства с организацией самоуправления в Швейцарии и США, а также на представления о земском опыте дореволюционной России. Впоследствии писатель неоднократно возвращался к этой волнующей его тематике.

Оригинальные идеи А.И. Солженицына о местном самоуправлении заключают в себе прежде всего утверждение его как института гражданского общества, лежащего в основе всей системы государственного устройства, «школы управления» и «школы политики». Писатель призывал к развитию прямой демократии, возможной в масштабах поселений, справедливо считая ее более эффективной формой воспитания ответственности за положение дел на местах, нежели демократия представительная.

А.И. Солженицын исповедовал идею деполитизированной системы местного самоуправления, основанной на поселенческом принципе и личном доверии, наиболее приближенной к жителям. Более того, ее он расценивал как базовую ступень всего государственного устройства, выстроенного снизу вверх «всероссийского земства».

Важно, что российская власть на высшем уровне прислушивалась к мнению Нобелевского лауреата. 12 июня 2007 г. А.И. Солженицыну была заочно вручена Государственная премия РФ; В.В. Путин лично посетил писателя, чтобы поздравить его с этим событием. Президент беседовал с Александром Солженицыным о текущем положении России и о будущем государства. Путин обратил внимание, что некоторые шаги, которые предпринимаются властью, созвучны тому, что писал Солженицын. В свою очередь А. Солженицын обратил внимание на то, что муниципалитетам предоставляется все больше возможностей ${ }^{1}$. Через несколько месяцев писателя не стало.

В одном из своих последних интервью Александр Солженицын признавал, что современная Россия по государственному устройству, своему общественному состоянию и экономическому положению весьма далека от его идеала. Это страна со своими недостатками и со своим обязанностями к развитию ${ }^{2}$. Писатель настаивал на исключении партийного начала из практики самоуправления, вывода его из-под диктата региональной власти. «Без правильно поставленного местного самоуправления не может быть добропрочной жизни, да и само понятие "гражданской свободы” теряет смысл», - был уверен писатель [Солженицын 1995: 589].

Именно эти слова Солженицына цитирует В.В. Путин в своей предвыборной статье «Демократия и качество государства» ${ }^{3}$, излагающей концептуальное представление о роли местного самоуправления в государственном управлении и общественной жизни. Раздел о местном самоуправлении имеет красноречивый подзаголовок: «Местное самоуправление - школа демократии». Местное самоуправление видится прежде всего как действенный институт, демократия малых пространств и власть шаговой доступности. Подчеркивалась необходимость прямой подотчетности местных властей жителям. Наряду с этим в статье был сделан акцент на обеспечении партнерских взаимодействий губернаторов с мэрами, региональными и городскими законодательными собраниями.

Высказанные принципы становления независимой и при этом подотчетной жителям власти на местах получил развитие и в последующих публичных выступлениях президента РФ. В его послании 2012 г. ставилась цель развития

1 Владимир Путин встретился с Александром Солженицыным. - Президент России. Официальный сайт. 12.06.2007. Доступ: http://www.kremlin.ru/events/president/news/40495.

2 «Я мечтал о другой России». Интервью Александра Солженицына программе «Вести недели». - Нобелевские лауреаты по литературе. 09.12.2007. Доступ: http://noblit.ru/ node/1284 (проверено 15.05.2020).

3 Путин В.В. Демократия и качество государства. - Коммерсант. 06.02.2012. 
прямой демократии, непосредственного народовластия ${ }^{1}$; в послании 2013 г. как один из приоритетов было определено повышение уровня доверия жителей: «Местная власть должна быть устроена так - а ведь это самая близкая власть к людям, - чтобы любой гражданин, образно говоря, мог дотянуться до нее рукой» ${ }^{2}$. Подчеркивалось, что через механизм выборов во власть должны приходить подготовленные, целеустремленные, профессиональные люди.

В этих рамках законодательно был введен новый вид муниципальных образований, которые могут быть созданы в соответствии с законом субъекта РФ, городской округ с внутригородским делением и городской район соответственно $^{3}$. Тем самым были созданы правовые возможности для того, чтобы приблизить к жителям муниципальный уровень власти в больших городах. Справедливости ради надо сказать, что к подобному муниципальному устройству перешли всего три российских города - Челябинск, Самара и Махачкала.

Поправки, внесенные в 2014 г. в федеральный закон «Об общих принципах организации местного самоуправления в Российской Федерации», существенно повысили роль региональной власти в построении структуры местной власти: способ формирования, содержание и срок полномочий, подотчетность и подконтрольность органов МСУ определяются уставом муниципального образования в соответствии с региональным законодательством. Кроме того, региональная власть получила возможность определять модель управления муниципалитетами: избрание глав муниципальных образований голосованием жителей или же делегирование этого права представительному органу, после чего отмена прямых выборов мэров стала массовой. По мнению исследователей, распространение модели «совет - менеджер» стало элементом авторитарной трансформации субнационального уровня российской политики и не привела к видимому повышению эффективности местного управления [Golosov, Gushchina, Kononenko 2016: 523]. Также поправки, внесенные в закон № 131, наделили региональную власть правом перераспределять некоторые полномочия между субъектом федерации и муниципалитетом.

Позже федеральный закон ${ }^{4}$ расширил перечень способов избрания местных представительных органов и наделения полномочиями глав муниципалитетов, из числа которых субъект РФ вправе выбирать наиболее оптимальный для себя: теперь высшее должностное лицо муниципального образования может избираться представительным органом муниципального образования из числа кандидатов, представленных конкурсной комиссией по результатам конкурса. Повсеместное распространение приобрело разделение постов главы муниципального образования (мэра) и главы городской администрации, внедрение

1 Послание Президента РФ Федеральному Собранию. - Президент России. Официальный сайт. 12.12.2012. Доступ: http://www.kremlin.ru/events/president/ news/17118 (проверено 15.05.2020).

2 Там же.

3 Федеральный закон от 27.05.2014 № 136-Ф3 «О внесении изменений в статью 26.3 Федерального закона "Об общих принципах организации законодательных (представительных) и исполнительных органов государственной власти субъектов Российской Федерации” и Федеральный закон “Об общих принципах организации местного самоуправления в Российской Федерации”». - Российская газета. № 121. 30.05.2014.

4 Федеральный закон от 20.03.2011 № 38-Ф3 «О внесении изменений в статьи 35 и 38 Федерального закона "Об основных гарантиях избирательных прав и права на участие в референдуме граждан Российской Федерации” и в Федеральный закон “Об общих принципах организации местного самоуправления в Российской Федерации" в связи с применением пропорциональной избирательной системы на выборах депутатов представительных органов муниципальных районов и городских округов». Доступ: http://www.kremlin.ru/ acts/bank/32822 (проверено 15.05.2020). 
института наемного сити-менеджера. При этом еще с 2011 г. на муниципальных выборах депутатов городского округа либо муниципального района допускается распределение части мандатов по партийным спискам, что расширяет партийный принцип в организации местного самоуправления.

Известные события 2014 г. на определенное время переключили внимание власти с внутренней повестки на внешнеполитическую. В дальнейшем в сфере МСУ вновь на первый план вышли вопросы вовлечения жителей в процесс местного самоуправления. На очередном заседании Совета по развитию местного самоуправления, состоявшемся 5 августа 2017 г. в Кирове, приоритетом в работе местной власти был назван диалог, стремление получить обратную связь ${ }^{1}$. Практическим полем взаимодействия местной власти и жителей стало благоустройство общественных пространств в рамках реализации федерального проекта по формированию комфортной городской среды. На Всероссийском совете местного самоуправления 25 декабря 2017 г. президент РФ призвал более активно привлекать к этой работе молодежь, а также поощрять общественные инициативы ${ }^{2}$. В своем предвыборном послании 2018 г. В.В. Путин озвучил основополагающую мысль: «Именно вовлеченность людей в дела страны и гражданская активность, как и культурные, нравственные, духовные ценности, делают нас единым народом, способным к достижению больших целей» ${ }^{3}$.

Таким образом, развитие местного самоуправления, с одной стороны, было вписано в общий тренд развития демократии и гражданского общества (что подчеркивает его «низовую», самоорганизующуюся природу), с другой - увязано с вопросами создания комфортной среды проживания.

При этом в законодательство о местном самоуправлении вносятся важные изменения. В апреле 2017 г. Владимир Путин подписал федеральный закон, разрешающий региональным властям проводить преобразование муниципальных районов в городские округа с упразднением двухуровневой системы организации местного самоуправления ${ }^{4}$. На заседании Совета при Президенте РФ по развитию гражданского общества и правам человека 27 апреля 2017 г. прошло обсуждение проблем и перспектив реализации в этом контексте права граждан на участие в местном самоуправлении, где была дана резко негативная оценка этой новации; указывалось, что декларируемые задачи повышения эффективности управления территориями «не соответствуют предназначению и сущности местного самоуправления как формы осуществления населением своей власти для самостоятельного решения вопросов местного значения, 〈...> важнейшего института согласования интересов населения и бизнеса во благо именно населения» 5 .

1 Заседание Совета при Президенте по развитию местного самоуправления. - Президент России. Официальный сайт. 05.08.2017. Доступ: http://www.kremlin.ru/events/councils/55301 (проверено 15.05.2020).

2 Приветствие участникам VI съезда Общероссийской общественной организации «Всероссийский Совет местного самоуправления». - Президент России. Официальный сайт. 25.12.2017. Доступ: http://www.kremlin.ru/events/president/letters/56481 (проверено 15.05.2020).

3 Послание Президента РФ Федеральному Собранию. - Президент России. Официальный caŭm. 01.03.2018. Доступ: http://www.kremlin.ru/events/president/news/56957 (проверено 15.05.2020).

4 Федеральный закон от 03.04.2017 № 62-Ф3 «О внесении изменений в Федеральный закон "Об общих принципах организации местного самоуправления в Российской Федераџии”». - Российская газета. № 71. 05.04.2017.

5 Рекомендации Совета при Президенте РФ по развитию гражданского общества и правам человека по итогам 53-го специального заседания на тему «Право граждан на участие в местном самоуправлении: проблемы и перспективы». 24.04.2017. Доступ: http:// president-sovet.ru/documents/read/562/ (проверено 15.05.2020). 
На первый взгляд, мы видим разнонаправленные и противоречивые тенденции в развитии института МСУ в России. Отправной точкой муниципальной реформы 2003 г. была идея приближения местной власти к населению. Предполагалось, что таким образом система управления на местах станет более гибкой и сможет эффективнее решать вопросы непосредственного жизнеобеспечения. Число муниципалитетов в РФ возросло вдвое. Почти сразу после этого начался процесс объединения муниципальных образований, вышедший на новый уровень в связи с распространением модели городских округов.

При этом на официальном уровне в качестве приоритета выдвигается укрепление связи органов местного самоуправления с населением, повышение их открытости для гражданских инициатив на местах, развитие доверия жителей к нижнему уровню публичной власти. Для снятия этого противоречия следует принять во внимание задачи, решаемые публичной властью во всей ее полноте. В самом кратком виде их можно представить как обеспечение национальной безопасности и повышение качества жизни граждан. На уровне местных сообществ эти задачи решаются преимущественно в форме реализации разнообразных программ социально-экономического развития территории. Жители вправе требовать от муниципалитетов, в которых они проживают, более качественных и дешевых услуг. Удовлетворение данного запроса требует укрупнения муниципалитетов, которое становится необходимым следствием технического и финансового развития. На современном этапе дробность управленческой структуры становится препятствием для эффективного функционирования системы муниципального управления: подавляющее число российских муниципалитетов нижнего и даже районного уровня не располагают собственными ресурсами для исполнения возложенных на них полномочий.

Как отмечают исследователи, за рубежом достаточно активно происходит трансформация территориальных основ организации местного самоуправления в соответствии с необходимостью повышения эффективности оказываемых местными властями услуг и снижения их себестоимости. Укрупнение муниципальных образований было повсеместным уже в послевоенной Европе [Целищева 2014: 19]. Очередной импульс эти процессы получили в начале XXI в. Так, в Греции число муниципалитетов сократилось в 18 раз; в Дании осталось всего 98 муниципалитетов [Либоракина 2003: 234]. По тому же пути пошли и постсоветские государства, имевшие сходный с Россией опыт создания системы местного самоуправления «с чистого листа»: в Латвии был ликвидирован районный уровень местного самоуправления, его полномочия перешли «вниз», к укрупненным общинам, а общее число муниципалитетов уменьшилось с 500 до 118. В Грузии, напротив, был упразднен низший уровень самоуправления сельский и поселковый, базовым звеном местного самоуправления здесь стали 65 крупных муниципалитетов - бывших муниципальных районов ${ }^{1}$.

В Соединенных Штатах более $80 \%$ населения проживает в урбанизированных агломерациях (метрополитенские ареалы), в которых действует большое число органов муниципального управления и муниципальных корпораций, координация между которыми весьма затруднительна. Множественность юрисдикций ведет также к утрате субъективного чувства местного сообщества, потере интереса жителей к местному самоуправлению [Черкасов 2015: 151-153].

Даже в Швейцарии - еще одной стране, которая упоминалась

1 Сидоренко С. Реформа, которой не избежать Украине: 10 примеров объединения общин в странах Европы. - Українська правда. 27.12.2017. Доступ: https://inosmi.ru/politic/20171227/241111675.html (проверено 15.05.2020). 
А.И. Солженицыным в качестве эталона непосредственной демократии, только с 2000 по 2014 г. стало на $20 \%$ муниципалитетов меньше ${ }^{1}$.

Если в западных странах старые общины стали слишком малы для новых реалий, но при этом новые технологии оказались способными обеспечить доступность местной власти безотносительно к размеру муниципалитета, то в России понятие местного сообщества как активного субъекта местного самоуправления до настоящего времени практически не использовалось. Муниципальное образование как правовая и управленческая категория существует прежде всего в территориальном, а не социальном измерении. Соответственно, укрупнение муниципальных образований может рассматриваться как механический процесс экономически обусловленного изменения политико-административных границ. При этом следует иметь в виду, что укрупненные муниципалитеты также будут нуждаться в современных социальных технологиях вовлечения жителей в процесс местного самоуправления, таких, например, как публичные слушания, «народный бюджет», местные референдумы и проекты поддержки местных инициатив. Особое место в этом ряду отведено территориальному общественному самоуправлению как уникальной форме самоорганизации жителей на уровне локального сообщества.

В свое время А.И. Солженицын акцентировал внимание на непосредственном участии жителей в самоуправлении - прямой демократии, или же «демократии малых пространств». Очевидно, что практическая реализация этого пожелания должна базироваться на наличии мелких самоорганизующихся и самоуправляющихся объединений внутри городских и сельских поселений, остающихся преимущественно формальными территориальными единицами.

Стартовавшая в 2020 г. конституционная реформа затронула основы организации местного самоуправления. Согласно новой редакции гл. 8, «органы местного самоуправления и органы государственной власти входят в единую систему публичной власти в Российской Федерации» 2 . В рамках своего визита в Череповец В.В. Путин развернуто прокомментировал реформы в сфере организации местного самоуправления. По мнению президента, «должна быть единая система публичной власти, чтобы у верхних этажей этой власти была ответственность за то, что происходит внизу, а те, кто работает в муниципалитетах, были связаны определенным образом со страной и ее интересами» 3 .

Из вышеизложенного видно, что в эволюции института местного самоуправления развитие вертикальных связей с уровнями государственной власти преобладает над совершенствованием горизонтальных сетевых взаимодействий. Однако вовлечение жителей в решение местных проблем по-прежнему остается актуальным. Необходимый баланс «вертикальной» и «горизонтальной» проекции института МСУ должен найти свое отражение в обновленных Основах государственной политики в области местного самоуправления до 2030 года, разработка которых была поручена правительству РФ по итогам очередного заседания Совета по развитию местного самоуправления, прошедшего

1 Муниципалитетов в Швейцарии становится меньше. - Швейцария Деловая. 05.01.2014. Доступ: https://business-swiss.ch/2014/01/gemeindefusion-ch/ (проверено 15.05.2020).

2 Закон РФ о поправке к Конституции РФ от 14.03.2020 N 1-ФК3 «О совершенствовании регулирования отдельных вопросов организации и функционирования публичной власти» от 14.03.2020 N 1-ФК3. Доступ: http://www.consultant.ru/document/cons_doc_LAW_346019/ (проверено 15.05.2020).

3 Встреча с представителями общественности. - Президент России. Официальный сайm. 04.02.2020. Доступ: http://www.kremlin.ru/events/president/news/62726 (проверено 15.05.2020). 
30 января 2020 г. $^{1}$ Вкупе с расширяющимся кругом неполитической гражданской активности (волонтерское движение, общественные проекты и т.п.) это создает социальную ткань, необходимую для полнокровной жизни подлинного местного самоуправления.

\title{
Список литературы
}

Либоракина М.И. 2003. Зарубежный опыт организации местного самоуправления. - Полития. № 4(31). С. 225-237.

Меркулов П.А., Васютин Ю.С., Ливцов В.А., Цыбаков Д.Л. 2018. Общинное и местное самоуправление: история от Античности до Новейшего времени: научная монография. Орел: Изд-во Среднерусского института управления - филиала РАНХиГС. $240 \mathrm{c.}$

Солженицын А.И. 1995. Как нам обустроить Россию (посильные соображения). - Публицистика: в 3 т. Ярославль: Верхняя Волга. Т. 1. С. 538-599.

Целищева Е.Ф. 2014. Тенденции изменения территориальной организации местного самоуправления в регионах России и за рубежом. - Муниципалитет: экономика и управление. № 3(8). С. 13-21.

Черкасов А.И. 2015. Местное управление в США: современные проблемы и перспективы. - Труды Института государства и права РАН. № 6. С. 147-167.

Golosov G.V., Gushchina K., Kononenko P. 2016. Russia's Local Government in the Process of Authoritarian Regime Transformation: Incentives for the Survival of Local Democracy. - Local Government Studies. Vol. 42. Is. 4. P. 507-526.

BUKALOVA Svetlana Vladimirovna, Cand.Sci. (Hist.), Associate Professor; Associate Professor of the Chair of Political Science and Public Policy, Central Russian Institute of Management - Branch of Russian Presidential Academy of National Economy and Public Administration (5a Blv Pobedy, Orel, Russia, 302028; stl1612@yandex.ru)

MERKULOVA Kseniya Gennadievna, Cand.Sci. (Pol.Sci.), Associate Professor; Associate Professor of the Chair of Political Science and Public Policy, Central Russian Institute of Management - Branch of Russian Presidential Academy of National Economy and Public Administration (5a Blv Pobedy, Orel, Russia, 302028; kseniia.merkulova@gmail.com)

\section{«DEMOCRACY OF SMALL SPACES»: EVOLUTION OF THE INSTITUTE OF LOCAL SELF-GOVERNMENT IN RUSSIA IN THE CONTEXT OF A.I. SOLZHENITSYN'S IDEAS}

\begin{abstract}
The institute of local self-government in modern Russia stay in a plight of permanent transformation and clarification of its organizational, social, political and legal foundations. These conditions require defining the ideological basis of the local self-government development, which underlies the interaction of local authorities with regional and federal state power, as well as with the folk. The modern Russian system of autonomous local self-government was created as the opposite to the Soviet system of unified state power. A.I. Solzhenitsyn, Nobel Laureate and public figure, defined local self-government as a depoliticized institution based on the settlement principle and personal trust, closest to the residents. Solzhenitsyn's term "democracy of small spaces" is often used in official speeches in relation to local self-government. Up to now, the current task of state policy in the field of local self-government is to involve residents in local self-government and increase the responsibility of local authorities to residents. The authors conclude that the further evolution of the local self-government institution should be determined by the balance of vertical connections in the system of public power and horizontal network interactions.
\end{abstract}

Keywords: local self-government, state policy, municipal reform, direct democracy, A.I. Solzhenitsyn

1 Заседание Совета по развитию местного самоуправления. - Президент России. Официальный сайт. 30.01.2020. Доступ: http://www.kremlin.ru/events/president/news/62701 (проверено 15.05.2020). 